In Terebratulina retusa, Gryphus vitreus and Macandrevia cranium, abfrontal cilia are present on the filaments and these beat continuously toward their tips.

From work now in progress, it would seem that Orton $^{2}$ was justified in his general inference from a detailed knowledge of Crania, and a limited knowledge of Gryphus vitreus (= Terebratula vitrea) and Argiope, that "the main current through the mantle cavity in brachiopods is produced chiefly by the lateral cilia on the gill filaments". It would also seem probable that reversal of the frontal currents on the filaments will be found in brachiopods generally.

This work was done while holding a Leverhulme Research Fellowship.

The Laboratory,

Citadel Hill,

Plymouth.

Dee. 5.

${ }^{1}$ Richards, J. R., Nature, 184, 367 (1949); J. Morph., 90, 65 (1952). "Orton, J. H., J. Mar. Biol. Assoc., U.K., (N.S.), 10, 283 (1914).

${ }^{3}$ Atkins, D., Quart. J. Micro. Sci., 79, 181 (1936); 79, 339 (1937a); ${ }^{m 9}, 375$ (1937b).

"Borg, F, Zool. Bidrag. Uppsala, 10, 181 (1926).

\section{Reversal of Mating Preference by Crossing Strains of Drosophila melanogaster}

Sexual selection may be an important component of the selection pressures determining changes of gene frequency in Mendelian populations, and a number of studies of Drosophila have been made with the object of assessing degree of competition for mates (see, for example, refs. 1 and 2) and have led to the conclusion that, while male vigour is an important factor, discrimination and preference between genotypes do occur and seem to be largely female attributes. In an attempt to assess the importance of mating preference as a factor affecting changes of gene frequency in some experimental populations described elsewhere ${ }^{3}$, we have come across a phenomenon which, as far as we can discover, has not been reported before.

We wished to test the preference of $w / w, w^{a} / w^{x}$ and $w / w^{a}$ females for $w^{a}$ or $w$ males in two separate environments (one constant $25^{\circ} \mathrm{C}$., the other $25^{\circ}$ during the day and $15^{\circ}$ during the night). The flies were obtained from stock cultures, the $w / w^{a}$ females by crossing. Each female to be tested was placed in a food tube with one male of each lkind for two days, and her offspring were grown and classified according to genotype of father. Failures were ignored and double matings were scored $\frac{1}{2}$. Three replicate tests gave the combined results shown in Table 1.

Over all the experiments, the two types of male have equal success $\left(\chi^{2}(1)=0.3810, p, 0 \cdot 7-0.5\right)$;

$$
\text { Table } 1
$$

\begin{tabular}{|c|c|c|c|c|c|c|}
\hline \multirow{2}{*}{$\frac{\text { Environment: }}{\begin{array}{l}\text { Successful } \\
\text { male : }\end{array}}$} & \multicolumn{2}{|c|}{$25^{\circ} \mathrm{C}}$. & \multicolumn{2}{|c|}{$15-25^{\circ} \mathrm{C}$} & \multicolumn{2}{|r|}{ Total } \\
\hline & $w$ & wa Total & $w$ & $w a$ Total & $w$ & wa Total \\
\hline $\begin{array}{c}\text { Type of } \\
\text { female } \\
w / w \\
w a / w^{a} \\
\text { Total }\end{array}$ & $\begin{array}{r}7 \cdot 0 \\
14 \cdot 5 \\
21 \cdot 5\end{array}$ & $\begin{array}{ll}19 \cdot 0 & 26 \cdot 0 \\
14 \cdot 5 & 29 \cdot 0 \\
33 \cdot 5 & 55 \cdot 0\end{array}$ & $\begin{array}{r}10 \cdot 0 \\
9 \cdot 0 \\
19 \cdot 0\end{array}$ & $\begin{array}{cc}17 \cdot 0 & 27 \cdot 0 \\
19 \cdot 0 & 28 \cdot 0 \\
36 \cdot 0 & 55 \cdot 0\end{array}$ & $\begin{array}{l}17 \cdot 0 \\
23 \cdot 5 \\
40 \cdot 5\end{array}$ & $\begin{array}{rr}36 \cdot 0 & 53 \cdot 0 \\
33 \cdot 5 & 57 \cdot 0 \\
69 \cdot 5 & 110 \cdot 0\end{array}$ \\
\hline$w / w a$ & $18 \cdot 0$ & $10 \cdot 0 \quad 28 \cdot 0$ & $21 \cdot 5$ & $8 \cdot 5 \quad 30 \cdot 0$ & $39 \cdot 5$ & $18 \cdot 5 \quad 58 \cdot 0$ \\
\hline Total & $39 \cdot 5$ & $43 \cdot 583 \cdot 0$ & $40 \cdot 5$ & $44 \cdot 5 \quad 85 \cdot 0$ & $80 \cdot 0$ & $88 \cdot 0 \quad 168 \cdot 0$ \\
\hline
\end{tabular}

but there is significant heterogeneity within the data $\left(\chi^{2}{ }_{(6)}=18.843, p<0.01\right)$. All this heterogeneity is associated with the degree of freedom for difference between the $w / w^{a}$ females and the two homozygous female types $\left(\chi^{2}{ }_{(1)}=13.660, p<0.001\right.$; residual $\left.\left.\chi^{2}{ }_{5}\right)=5 \cdot 183, p \simeq 0 \cdot 3\right)$, and the difference is in the direction that $w / w^{a}$ females prefer $w$ males, whereas both $w^{a} / w^{a}$ and $w / w$ females prefer $w^{a}$ males. The respective degrees of preference are about equal : 0.7 of the $w / w^{a}$ matings were with $w, 0.6$ of the $w^{a} / w^{a}$ matings were with $w^{a}$ and $0 \cdot 7$ of the $w / w$ matings were with $w^{a}$.

There is thus a remarkable difference between the mating preferences of the two types of stock female and the females produced by crossing these stocks. We cannot, of course, associate it with the marker locus, for it may be associated with genes or gene complexes anywhere in the chromosome complement. However, the observation that mating preference may be reversed by hybridization, even though the types hybridized have similar preferences, is striking. If such reversal of preference were associated with a single locus or small block of chromatin it could, in certain circumstances, be responsible for a stable polymorphism.

Department of Genetics,

G. TEBB*

J. M. THODAY

University of Sheffield.

Dee. 7.

- Now on the staff of the Poultry Research Centre of the Agricultural Researeh Council, Edinburgh 9.

${ }^{1}$ Wallace, B., and Dobzhansky, Th., Proc. U.S. Nat. Acad. Sci., 32, 226 (1946).

${ }^{2}$ MerreIl, D. J., Genetics, 34, 370 (1949).

${ }^{3}$ Tebb, G., andjThoday, J. M., Proc. IX Int. Cong. Genet. (in the press).

\section{A Simple Potometer for measuring Rate of Water Uptake by Small Seeds}

THE usual method of measuring rate of water uptake by soeds is to weigh samples after different periods of imbibition. This method is not free from errors as the seeds have to be freed from adherent water before weighing, which cannot be done aceurately, and, during handling and woighing, loss of water always occurs by evaporation. Furthermore, different lots of seeds have to be used for the various measurements, which is cumbersome and a disadvantage in cases where only small amounts of seeds are available.

Kruyt ${ }^{1}$ measured water uptake by enclosing the seeds in a water-filled bottle, through the stoppered mouth of which protruded a capillary tube. By watching the fall of the water column in this capillary, water uptake was measured. In this method the seeds are totally submerged, and no attention is given to volume changes of the seeds due to swelling.

In order to determine germination-rate or metabolic changes in small and quickly germinating seeds, the seeds are usually not submerged, but are placed on wet filter paper. When water uptake has to be correlated with findings obtained by this method, the seeds ought not to be submerged, as this treatment changes their germination behaviour. The potometer described here allows water uptake to be measured in a single lot of seeds imbibing on wet filter paper during a prolonged period of time without weighing.

The edge of a P'etri dish is ground and a hole blown in the middle of the bottom. A capillary tube about $65-70 \mathrm{~cm}$. long is sealed to the hole and bent 